\title{
Identification of Atherosclerotic Changes Using B-Mode Ultrasonography in Nigerian Children with Type 1 Diabetes Mellitus
}

\author{
0.0. Ayoola ${ }^{1}$, J.B.E. Elusiyan ${ }^{2}$, T.A. Adedeji ${ }^{3}$ \\ ${ }^{1}$ Department of Radiology, Obafemi Awolowo University, Ile-Ife, Nigeria \\ ${ }^{2}$ Department of Paediatrics and Child health, Obafemi Awolowo University, Ile-Ife, Nigeria \\ ${ }^{3}$ Department of Chemical Pathology, Obafemi Awolowo University, Ile-Ife, Nigeria \\ Email: *oluyoola@yahoo.com
}

How to cite this paper: Ayoola, O.O., Elusiyan, J.B.E. and Adedeji, T.A. (2017) Identification of Atherosclerotic Changes Using B-Mode Ultrasonography in Nigerian Children with Type 1 Diabetes Mellitus. Journal of Diabetes Mellitus, 7, 142150.

https://doi.org/10.4236/jdm.2017.73011

Received: July 1, 2017

Accepted: August 8, 2017

Published: August, 11, 2017

Copyright $\odot 2017$ by authors and Scientific Research Publishing Inc. This work is licensed under the Creative Commons Attribution International License (CC BY 4.0).

http://creativecommons.org/licenses/by/4.0/

\begin{abstract}
Background: This study aimed at documenting the degree of atherosclerosis, which is an important macrovascular complication in Nigerian children with Type 1 Diabetes Mellitus as determined by ultrasonography using the carotid, femoral and brachial arteries. Method: A prospective observational study was performed on all 10 children diagnosed with diabetes mellitus at the paediatric endocrinology clinic, in a tertiary unit based in Nigeria over a six-month period. Results: All 10 children were aged between $12-17$ years (Median $=16$ years) and consist of $5(50 \%)$ males and $5(50 \%)$ female. The duration of diabetes ranged from 0.2 to 9 years. Four (40\%) of the subjects had thickened carotid intima media thickness on either the left or right common carotid artery; $5(50 \%)$ had $0 \%$ flow mediated dilation of the brachial artery while the remaining 5 (50\%) had normal flow mediated dilation; while 2 (30\%) had intima media thickening of either the left or right superficial femoral artery using a cut-off value of $0.9 \mathrm{~cm}$. Conclusion: Children with Type 1 Diabetes Mellitus have ultrasonic evidence of ongoing atherosclerosis. The use of ultrasound is recommended for detection and monitoring of atherosclerotic changes in children with DM.
\end{abstract}

\section{Keywords}

Diabetes, Childhood, Atherosclerosis, Ultrasound

\section{Introduction}

Type 1 Diabetes Mellitus (DM) is a chronic metabolic condition characterized by hyperglycemia due to absolute insulin deficiency secondary to autoimmune 
destruction of the insulin-producing beta cells in pancreatic islets. Chronic inflammation in the islets, usually after years, and rarely in just months, leads to insulin-dependent diabetes [1]. Its management requires lifelong adherence to therapies and frequent interactions with healthcare professionals [2]. Cardiovascular disease (CVD) remains the leading cause of death in people with diabetes [3]. Hyperglycemia has also been associated with endothelial cell (EC) dysfunction and reduced neovascularization in response to tissue ischemia, processes that are essential for wound healing and prevention of cardiovascular ischemia [4]. Atherosclerosis is an important macrovascular complication and the major cause of morbidity and mortality in patients with DM [5]. Although type 1 diabetics are at lower risk for atherosclerotic cardiovascular disease than type 2 diabetics due to the younger age of the former group the relative risk is 10 times higher in type 1 diabetics than in non-diabetics of similar age. Elevated triglycerides, and albuminuria have also been reported to be associated with vascular complications in diabetes [6]. Several markers have been used reliably to assess atherosclerosis namely carotid intima media thickness (IMT) [7], brachial artery flow mediated dilation (FMD) [8] and femoral IMT with the use of ultrasonography.

The IMT is defined as the distance between the hyperechogenic inner (bloodintima interface) and outer line (media-adventitia interface) of the arterial wall. It is a surrogate marker of atherosclerotic damage [9]. Measuring of IMT using B-mode ultrasound has been shown to be a reliable predictor of early atherosclerosis and assessing the subsequent risk of vascular events [10] [11] [12]. Several population-based studies have revealed carotid IMT to be a reliable marker for predicting peripheral vascular disease (PVD) while there is paucity of data as to prove the link between increased femoral IMT and PVD [13].

The vascular endothelium plays a central role in regulating vasomotor tone, thrombosis, and platelet adhesion [14]. Endothelial dysfunction, a state of impairment of these regulatory functions, is one of the initial pathological processes of atherosclerosis and has been associated with an increase in cardiovascular risk [15] [16]. Brachial FMD is a validated, noninvasive physiological measure widely used as a research tool to quantify endothelial function [16]. FMD assessed by Doppler ultrasound has emerged as the most popular clinical research method of assessing vascular endothelial function, likely because of the relatively simple methodology and noninvasive nature [17].

Studies done in Mexico and Hungary have shown carotid IMT increase in patients with type $1 \mathrm{DM}$ especially in patients with glycated haemoglobin (HbAlc) values of greater than $8.5 \%$ [18] [19]. Type $1 \mathrm{DM}$ is still a very rare disease in Sub-Saharan Africa and as such there is paucity of information in the literature on the disease [20]. The few published works in Sub-Saharan African on DM in children has shown that these children face a lot of challenges in the management of their disease and also have poor outcome as evidenced by high $\mathrm{HbAlc}$ values [21] [22]. Poor control has also been shown to lead to early onset of both micro and macrovascular complications [23]. 
Early determination of these macrovascular and microvascular complications may allow for institution of appropriate preventive or early definitive therapeutic measures to ensure improved quality of life.

This study was conducted to document atherosclerotic changes in children with type $1 \mathrm{DM}$ by evaluating the carotid and femoral IMT along with the FMD of the brachial artery. To the best of our knowledge, there has not been any report of similar study from any Sub-Saharan country.

\section{Patient and Methods}

This study was a prospective hospital based observational study involving all the 10 children with a diagnosis of Type 1 DM being managed at the paediatric endocrinology. Ethical approval was obtained from the ethics committee of the institution. Consent was obtained from the parents and the children gave assent.

The subjects bio data such as initials, age, sex, and hospital number were obtained into a proforma designed for the study. The duration of illness, form of treatment were documented for the subjects. Their weight and height were measured according to standard techniques and their BMI calculated.

\section{Biochemical Assay}

Four mls of venous blood was drawn from each subject for fasting blood glucose, lipid profile, $\mathrm{HbA1c}$ and homocysteine (HCY); early morning urine samples were also obtained and analyzed for presence of albumin. A biochemical auto-analyzer (Cardiochek PA, USA) was used for assaying the serum lipid profile and fasting blood glucose; HbAlc was analyzed using Polymer technology systems, Inc, USA biochemical autoanalyzer. HCY was analyzed using Eliza kits (Neobiolab, MA, USA)

Urinary albumin-creatinine ratio (UACR) of a random spot urine was determined using CLINITEK microalbumin (Siemens Healthcare Inc, Camberly, $\mathrm{UK}$ ), a semi-quantitative strip test. UACR was calculated as albumin (mg)/creatinine (g). Normoalbuminuria, microalbuminuria and macroalbuminuria was defined as UACR of $<30 \mathrm{mg} / \mathrm{g}, 30-300 \mathrm{mg} / \mathrm{g}$ and $>300 \mathrm{mg} / \mathrm{g}$ respectively [24].

\section{Ultrasound Examination}

Ultrasound examination was done after an overnight fast on the carotid, femoral and brachial arteries using Mindray Ultrasound Scanning machine Model DC-7 with Doppler facilities and a linear array probe of $7.5 \mathrm{MHz}$ frequency.

The common carotid arteries were examined with the subjects in supine position and with the examiner seated next to the patient. The neck was exposed maximally by having the patient drop the ipsilateral shoulder as far as possible. Neck exposure was also optimized by rotating the head away from the side being examined. Coupling gel was then applied on the neck and scanning was done in longitudinal and transverse scanning planes using the anterior, lateral and postero-lateral approaches. All measurements of the carotid IMT were made on optimal longitudinal freeze-frame image of the common carotid artery in the end 
diastolic state. A gradual and gentle probing with a heel-toe technique was employed to display the double line effect of the lumen-intima and media-adventitia interfaces. The IMT defined by Pignoli et al. [25] was measured as the distance from the leading edge of the first echogenic line to the leading edge of the second echogenic line. IMT was measured in a $10-\mathrm{mm}$ long segment just proximal to the carotid bulb in the common carotid artery (Figure 1) and in a $15-\mathrm{mm}$ long segment just distal to the bifurcation in the common femoral artery. The computer program calculated the mean values of IMT from three separate images [26]. A value of $>$ or equal to $0.8 \mathrm{~cm}$ was adjudged to be thickened; this was a value of 2 standard deviations above the mean value obtained in a normal population of children in a study done by Hayaishi-Okano R et al. [7].

A standard paediatric blood pressure cuff was positioned around the right arm, 2 inches below the antecubital fossa, and the artery was imaged 5 to $9 \mathrm{~cm}$ above the antecubital fossa. A linear-array multifrequency transducer operating at $9 \mathrm{MHz}$ was used to acquire images of the right brachial artery. After baseline images were obtained, the cuff was inflated to $50 \mathrm{~mm} \mathrm{Hg}$ above the participant's systolic blood pressure for 4 minutes. Digitized images of the right brachial artery were captured 90 seconds after cuff deflation after which the brachial artery diameter was taken again. Percentage FMD was computed, as follows: \%FMD = [(maximum diameter-baseline diameter)/baseline diameter] $\times 100 \%$ [27].

\section{Results}

All 10 subjects attending the paediatric diabetes clinic were recruited into the study, from May till December 2014, and they consist of 5 (50\%) males with 5

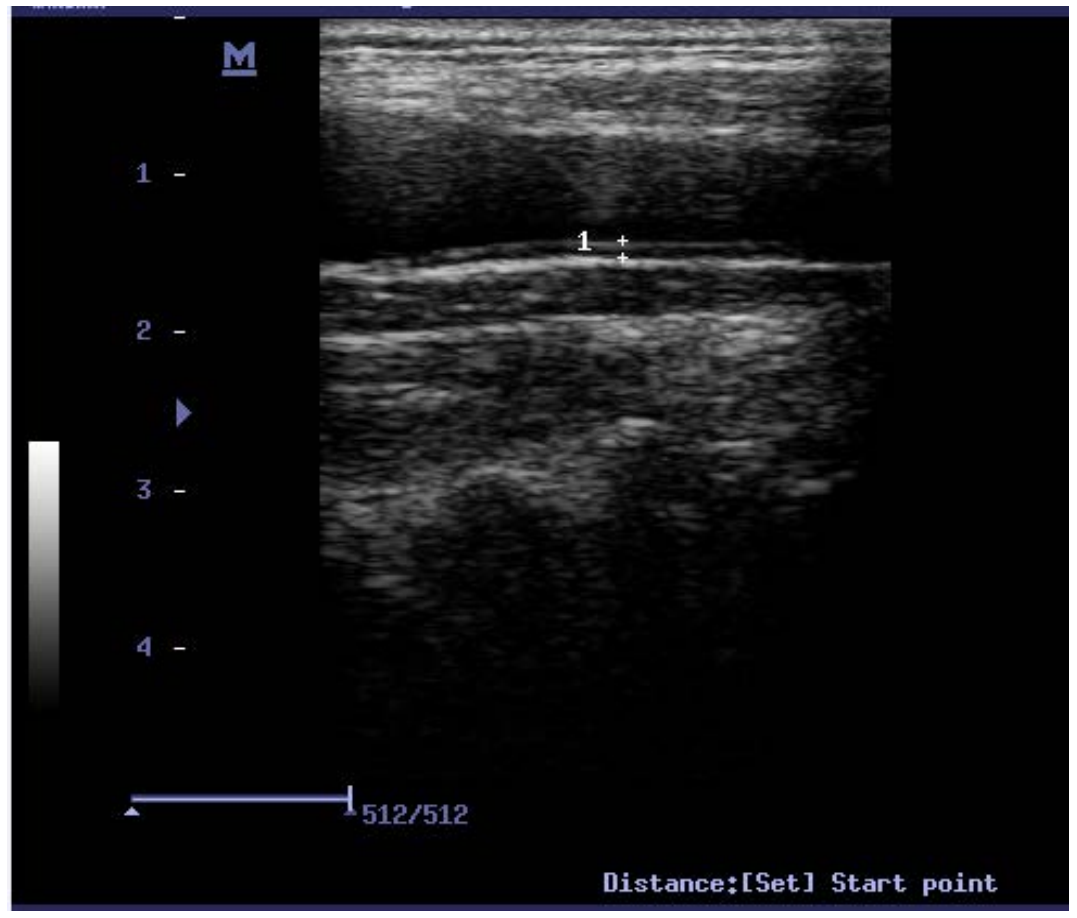

Figure 1. Measurement technique of obtaining carotid IMT on a Longitudinal B-mode ultrasound (calipers). 
(50\%) females with an age range of $12-17$ years and a median of 16 years. The duration of diabetes ranged from 0.2 to 9 years with a median of 3.5 years; the body mass index ranged from 14.0 to 24.7 , with a median of 18.15 ; fasting blood sugar ranged from 3.6 to $20 \mathrm{mmol} / \mathrm{L}$ with a median of $13.46 \mathrm{mmol} / \mathrm{L}$; HbAlc ranged from 8.6 to $13 \%$, with a median of $13 \%$; and $\mathrm{HCY}$ values ranged from 8.6 to $533.1 \mathrm{umol} / \mathrm{L}$ with a median of $32.95 \mathrm{umol} / \mathrm{L}$ (Table 1 ).

Two (20\%) of the subjects (Subjects $2 \& 5$ ) were underweight based on their BMI while the remaining $8(80 \%)$ had normal weights; none of them was obese. Using a cut-off value of $11.3 \mathrm{umol} / \mathrm{L}$ [28], $8(80 \%)$ of the subjects would be adjudged to have hyperhomocysteinemia. Only 2 (20\%) of subjects had hypercholesterolemia using a cut-off value of $5 \mathrm{mmol} / \mathrm{L}$ for TC (Subjects $3 \& 6$ ); while only 1 (10\%) subject had a cut-off value of above $4 \mathrm{mmol} / \mathrm{L}$ for LDL (Subject 6).

Spot urine assessment for albumin showed $4(40 \%)$ of the subjects had normoalbuminuria ( $<30 \mathrm{mg} / \mathrm{g}), 3(30 \%)$ had microalbuminuria $(30-300 \mathrm{mg} / \mathrm{g})$ and $3(30 \%)$ had macroalbuminuria $(>300 \mathrm{mg} / \mathrm{g})$. In all $6(60 \%)$ of the subjects had albuminuria ( $>30 \mathrm{mg} / \mathrm{g}$ ).

The percentage FMD ranged between $0 \%$ to $10.53 \%$ with a median of $1.61 \%$; Five (50\%) of the subjects had some degree of dilation of the brachial artery while the remaining $5(50 \%)$ had a $0 \%$ FMD indicating no dilation of the brachial artery following occlusion.

The carotid IMT ranged from 0.51 to $0.92 \mathrm{~cm}$ on the right and from 0.60 to $0.91 \mathrm{~cm}$ on the left (median values were 0.65 and $0.715 \mathrm{~cm}$ on the right and left respectively). Four (40\%) of the diabetics had a value of above $0.8 \mathrm{~cm}$, which was a value of 2 standard deviations above the mean value obtained in a normal population of children in a study done by Hayaishi-Okano $\mathrm{R}$ et al. [7]. Three

Table 1. Demographic, biochemical and sonographic parameters of type 1 diabetic subjects.

\begin{tabular}{ccccccccccccccc}
\hline S/N & Sex & Age & BMI & HbAlc & HCY & UACR & TC & LDL & $\begin{array}{c}\text { LCCA } \\
\text { IMT }\end{array}$ & $\begin{array}{c}\text { RCCA } \\
\text { IMT }\end{array}$ & $\begin{array}{c}\text { FMD } \\
\text { FMFA }\end{array}$ & $\begin{array}{c}\text { RMT } \\
\text { IMFA }\end{array}$ \\
\hline $\mathbf{1}$ & M & 17 & 17.8 & 13 & 30.5 & $>300$ & 2.59 & 1.66 & 0.91 & 0.74 & 0.0 & 0.54 & 0.56 \\
$\mathbf{2}$ & F & 16 & 14 & 13 & 246.6 & $30-300$ & 3.09 & 2.19 & 0.72 & 0.66 & 6.06 & 0.51 & 0.63 \\
$\mathbf{3}$ & F & 15 & 18.6 & 13 & 533.1 & $<30$ & 5.66 & 3.92 & 0.64 & 0.51 & 10.53 & 0.55 & 0.54 \\
$\mathbf{4}$ & M & 16 & 17.2 & 10.8 & 26.3 & $<30$ & 2.59 & 2.05 & 0.86 & 0.64 & 0.0 & 0.60 & 0.96 \\
$\mathbf{5}$ & $\mathrm{M}$ & 15 & 14.1 & 13 & 76.5 & $30-300$ & 3.75 & 2.42 & 0.7 & 0.92 & 0.0 & 0.72 & 0.55 \\
$\mathbf{6}$ & $\mathrm{F}$ & 16 & 18.9 & 8.6 & 10.3 & $<30$ & 6.07 & 4.65 & 0.72 & 0.65 & 9.52 & 0.73 & 0.64 \\
$\mathbf{7}$ & $\mathrm{M}$ & 17 & 18.3 & 8.5 & 89.3 & $<30$ & 4.07 & 2.45 & 0.71 & 0.67 & 8.0 & 0.93 & 1.12 \\
$\mathbf{8}$ & $\mathrm{F}$ & 17 & 17.5 & 13 & 22.4 & $>300$ & 2.75 & 1.9 & 0.6 & 0.52 & 0.0 & 0.53 & 0.54 \\
$\mathbf{9}$ & $\mathrm{M}$ & 17 & 24.7 & 12.6 & 8.6 & $>300$ & 3.12 & 1.87 & 0.83 & 0.65 & 0.0 & 0.53 & 0.56 \\
$\mathbf{1 0}$ & $\mathrm{F}$ & 12 & 18.6 & 13 & 35.4 & $30-300$ & 2.59 & 1.9 & 0.64 & 0.55 & 3.23 & 0.60 & 0.62 \\
\hline
\end{tabular}

The units of measurements were as follows: Age-years, HCY-umol/L, UACR-mg/g, TC and LDL-mmol/L, IMT-cm. BMI (Body mass index); HbAlc (Glycated Haemoglobin); HCY (Homocysteine); UACR (Urinary albumin-creatinine ratio); TC (Total cholesterol); LDL (low density lipoprotein); LCCA (left common carotid artery); RCCA (right common carotid artery); IMT (intima media thickness); LSFA (left superficial femoral artery); RSFA (right superficial femoral artery); FMD (flow mediated dilation). 
(75\%) of these subjects that had carotid intima media thickening were found to be on the left side while 1 (25\%) was discovered to be on the right.

The IMT in the superficial femoral arteries ranged from 0.51 to $0.93 \mathrm{~cm}$ on the left and 0.54 to $1.12 \mathrm{~cm}$ on the right (median values were 0.575 and $0.59 \mathrm{~cm}$ in the left and right sides respectively); 2 (20\%) of the subjects had intima media thickening on either side in regards to the superficial femoral arteries using a cut-off value of $0.8 \mathrm{~cm}$.

\section{Discussion}

Numerous studies have shown that patients with DM have accelerated atherosclerotic vascular disease [29]. This present study has also shown this to be true in paediatric population as well. Four (40\%) of the studied subjects were found to have an IMT value greater than $0.8 \mathrm{~mm}$ on either side of the carotid IMT (Figure 1), 2 (20\%) of the subjects had intima media thickening of the superficial femoral arteries and 5 (50\%) had degrees of dilation of the brachial artery following occlusion ranging from $3.23 \%$ to $10.53 \%$. The result of this study has shown that atherosclerotic changes are present in children with DM. There are several pathogenetic mechanisms of atherosclerosis including endothelial injury; platelet adherence to the site of injury; platelet aggregation at the site of injury; release from platelets of materials stored intra-cellularly; smooth muscle cell proliferation and migration into the subendothelial layer at the area of damage; accumulation of extracellular matrix (collagen, elastic tissue, glycosoaminoglycans); accumulation of lipids and lipoproteins; and thrombosis [29]. All these mechanisms have been shown to be common in children with DM.

The values of FMD of the brachial artery of $0.0 \%$ to $10.53 \%$ in the present study is less than those obtained for the healthy and diabetic adult population [8], however it should be noted that all the subjects in the present study are entirely a paediatric population.

Other significant predictors of IMT were age and LDL cholesterol in both sexes [30]. The correlation between age and carotid IMT has been shown to have an $r$ value of as high as $0.469(p<0.05)$ [31]. Total cholesterol was a significant childhood predictor in both sexes, while childhood body mass index was significant only in women. None of the subjects had BMI in the obesity range and only two of them (Subjects $3 \& 6$ ) were noted to have elevated TC and LDL levels but the IMT in both carotid and femoral arteries and percentage FMD in both of them were all normal.

Eight $(80 \%)$ of the subjects had hyperhomocysteinemia. Hyperhomocysteinemia has been documented to be a risk factor for coronary, cerebral, and peripheral vascular disease. Plasma HCY levels have been documented to be elevated in diabetics when there is atherosclerosis or insufficient renal function [32]. From the HbA1c values which revealed a median value of 13 , which was noted in $60 \%$ of the subjects, the hyperhomocysteinemia noted in $80 \%$ of the subjects may be explained by the poor glycaemic control which was further confirmed by poor compliance to insulin therapy. This poor metabolic control has been do- 
cumented in children managed for diabetes in Kenya too [22]. The hyperhomocysteinemia may also be explained by the renal impairment which diabetics are prone to having and which may be suspected in view of the presence of proteinuria in $6(60 \%)$ of the subjects. One of the 2 subjects that had normal HCY levels (Subject 6) had normoalbuminuria (Table 1). This finding in our study might lay credence to the fact that the IMT thickening would most likely be due to metabolic derangement of the diabetes and not due to the age, BMI or elevated cholesterol of the subject.

The major limitation of the present study is the small sample size which is due to the very low prevalence of the disease in our environment. Atherosclerotic changes as adjudged by ultrasonography were present in $60 \%$ of the subjects. This may reflect the development of long term complications in these children and as such urgent efforts need to be put in place to arrest the progression of these changes. Insulin availability and intensification of the management has been shown by the DCCT [23] study to be a beneficial way of arresting the complications associated with the disease. A follow-up study to monitor progression of these changes will also be imperative.

\section{References}

[1] Nokoff, N.J., Rewers, M. and Cree Green, M. (2012) The Interplay of Autoimmunity and Insulin Resistance in Type1 Diabetes. Discovery Medicine, 13, 115-122.

[2] Nokoff, N.J. and Rewers, M. (2013) Pathogenesis of Type 1 Diabetes: Lessons from Natural History Studies of High Risk Individuals. Annals of the New York Academy of Sciences, 1281, 1-5. https://doi.org/10.1111/nyas.12021

[3] Soedamah-Muthu, S.S., Fuller, J.H., Mulnier, H.E., Raleigh, V.S., Lawrenson, R.A. and Colhoun, H.M. (2006) High Risk of Cardiovascular Disease in Patients with Type 1 Diabetes in the UK: A Cohort Study Using the General Practice Research Database. Diabetes Care, 29, 798-804. https://doi.org/10.2337/diacare.29.04.06.dc05-1433

[4] Loomans, C.J., de Koning, E.J., Staal, F.J., Rookmaaker, M.B., Verseyden, C., de Boer, H.C., et al. (2004) Endothelial Progenitor Cell Dysfunction. Diabetes, 53, 195 199. https://doi.org/10.2337/diabetes.53.1.195

[5] Swerdlow, A.J. and Jones, M.E. (1996) Mortality during 25 Years of Follow-Up of a Cohort with Diabetes. International Journal of Epidemiology, 25, 1250-1261. https://doi.org/10.1093/ije/25.6.1250

[6] Makinen, V., Forsblom, C., Thorn, L. and Waden, J. (2008) Metabolic Phenotypes, Vascular Complications, and Premature Deaths in a Population of 4,197 Patients with Type 1 Diabetes. Diabetes, 57, 2480-2487. https://doi.org/10.2337/db08-0332

[7] Hayaishi-Okano, R., Yamasaki, Y., Katakami, N., Ohtoshi, K., Gorogawa, S.I., Kuroda, A., et al. (2002) Elevated C-Reactive Protein Associates with Early-Stage Carotid Atherosclerosis in Young Subjects with Type 1 Diabetes. Diabetes Care, 25, 1432-1438. https://doi.org/10.2337/diacare.25.8.1432

[8] Bots, M.L., Westerink, J., Rabelink, T.J. and de Koning, E.J. (2005) Assessment of Flow-Mediated Vasodilation (FMD) of the Brachial Artery: Effects of Technical Aspects of the FMD Measurement on the FMD Response. European Heart Journal, 26, 363-368. https://doi.org/10.1093/eurheartj/ehi017

[9] Bernetti, M., Abbate, R., Cerini, G., Gensini, G.F., Poggesi, L. and Boddi, M. (2011) 
Carotid and Femoral Intima-Media Thickness as an Early Atherosclerotic Marker. Advantages and Limits. Giornale Italiano di Cardiologia, 12, 72-81.

[10] Allan, P.L., Mowbray, P.I., Lee, A.J. and Fowkes, F.G. (1997) Relationship between Carotid Intima-Media Thickness and Symptomatic and Asymptomatic Peripheral Arterial Disease. The Edinburgh Artery Study. Stroke, 28, 348-353. https://doi.org/10.1161/01.STR.28.2.348

[11] Grobbee, D.E. and Bots, M.L. (1994) Carotid Artery Intima-Media Thickness as an Ultrasound Indicator of Generalized Atherosclerosis. Journal of Internal Medicine, 236, 567-573. https://doi.org/10.1111/j.1365-2796.1994.tb00847.x

[12] Kazmierski, R., Kozubski, W. and Watala, C. (2000) Intima-Media Complex Thickness of Common Carotid Artery as a Risk Factor for Stroke. Neurologia i Neurochirurgia Polska, 34, 243-253.

[13] Suurkula, M., Fagerberg, B., Wendelhag, I., Agewall, S. and Wikstrand, J. (1996) Atherosclerotic Disease in the Femoral Artery in Hypertensive Patients at High Cardiovascular Risk. The Value of Ultrasonographic Assessment of Intima-Media Thickness and Plaque Occurrence. Risk Intervention Study (RIS) Group. Arteriosclerosis, Thrombosis, and Vascular Biology, 16, 971-977. https://doi.org/10.1161/01.ATV.16.8.971

[14] Ross, E. (1999) Atherosclerosis: An Inflammatory Disease. The New England Journal of Medicine, 340, 115-126. https://doi.org/10.1056/NEJM199901143400207

[15] Widlanksy, M.E., Gokce, N., Keaney, J.F. and Vita, J.A. (2003) The Clinical Implications of Endothelial Dysfunction. Journal of the American College of Cardiology, 42, 1149-1160.

[16] Celermajer, D.S., Sorensen, K.E. and Gooch, V.M. (1992) Non-Invasive Detection of Endothelial Dysfunction in Children and Adults at Risk of Atherosclerosis. The Lancet, 340, 1111-1115.

[17] Harris, R.A., Nishiyama, S.K., Wray, D.W. and Richardson, R.S. (2010) Ultrasound Assessment of Flow-Mediated Dilation. Hypertension, 55, 1075-1085. https://doi.org/10.1161/HYPERTENSIONAHA.110.150821

[18] Gómez-Díaz, R.A., Ramírez-Soriano, E., Tanus Hajj, J. and Bautista Cruz, E. (2012) Association between Carotid Intima-Media Thickness, Buccodental Status, and Glycemic Control in Pediatric Type 1 Diabetes. Pediatric Diabetes, 13, 552-558. https://doi.org/10.1111/j.1399-5448.2012.00868.x

[19] Siró, P., Molnár, C., Katona, E., Antek, C. and Kollár, J. (2009) Carotid Intima-Media Thickness and Cerebrovascular Reactivity in Long-Term Type 1 Diabetes Mellitus. Journal of Clinical Ultrasound, 37, 451-456. https://doi.org/10.1002/jcu.20617

[20] Majaliwa, E.S., Elusiyan, J.B.E., Adesiyun, O.O., Laigong, P., Adeniran, K.A., Kandi, M.C., et al. (2008) Type 1 Diabetes Mellitus in African Population: Epidemiology and Management Challenges. Acta Biomedica, 79, 255-259.

[21] Elusiyan, J.B.E., Okeniyi, J.A.O. and Adegoke, S.A. (2008) Challenges of Managing Diabetes Mellitus in Nigerian Children. Nigerian Endocrine Practice, 2, 111-115.

[22] Ngwiri, T., Were, F., Predieri, B., Ngugi, P. and Iughetti, L. (2015) Glycaemic Control in Kenyan Children and Adolescents with Type 1 Diabetes Mellitus. International Journal of Endocrinology, 2015, Article ID: 761759.

https://doi.org/10.1155/2015/761759

[23] The Diabetic Control and Complications Trial Research Group (1993) The Effect of Intensive Treatment of Diabetes on the Development and Progression of Long Term Complications in IDDM. The New England Journal of Medicine, 14, 977-986. 
[24] Ninomiya, T., Perkovic, V., de Galan, B.E., Zoungas, S., Pillai, A., Jardine, M., et al. (2009) Albuminuria and Kidney Function Independently Predict Cardiovascular and Renal Outcomes in Diabetes. Journal of the American Society of Nephrology, 20, 1813-1821. https://doi.org/10.1681/ASN.2008121270

[25] Pignoli, P., Tremoli, E., Poli, A., Oreste, P. and Paoletti, R. (1986) Intima plus Medial Thickness of the Arterial Wall: A Direct Measurement with Ultrasound Imaging. Circulation, 74, 1399-1406. https://doi.org/10.1161/01.CIR.74.6.1399

[26] Held, C., Hjemdahl, P., Eriksson, S.V., Bjorkander, I., Forslund, L. and Rehnqvist, N. (2001) Prognostic Implications of Intima-Media Thickness and Plaques in the Carotid and Femoral Arteries in Patients with Stable Angina Pectoris. European Heart Journal, 22, 62-72. https://doi.org/10.1053/euhj.1999.2006

[27] Yeboah, J., Crouse, J.R., Hsu, F., Burke, G.L. and Herrington, D.M. (2007) Brachial Flow-Mediated Dilation Predicts Incident Cardiovascular Events in Older Adults. Circulation, 115, 2390-2397. https://doi.org/10.1161/CIRCULATIONAHA.106.678276

[28] Vilaseca, M.A., Moyano, D., Ferrer, I. and Artuch, R. (1997) Total Homocysteine in Pediatric Patients. Clinical Chemistry, 4, 690-692.

[29] Colwell, J.A., Lopes-virella, M. and Halushka, P.V. (1981) Pathogenesis of Atherosclerosis in Diabetes Mellitus. Diabetes Care, 4, 121-133.

https://doi.org/10.2337/diacare.4.1.121

[30] Davis, P.H., Dawson, J.D., Riley, W.A. and Lauer, R.M. (2001) Carotid IntimalMedial Thickness Is Related to Cardiovascular Risk Factors Measured from Childhood through Middle Age: The Muscatine Study. Circulation, 104, 2815-2819. https://doi.org/10.1161/hc4601.099486

[31] Ayoola, O.O., Onuwaje, M.A. and Akintomide, A.O. (2015) Sonographic Assessment of the Carotid Intima-Media Thickness on B-Mode Ultrasonography in a Nigerian Population. Nigerian Medical Journal, 56, 357-361. https://doi.org/10.4103/0300-1652.170384

[32] Schalinske, K.L. (2003) Interrelationship between Diabetes and Homocysteine Metabolism: Hormonal Regulation of Cystathionine [beta]-Synthase. Nutrition Reviews, 61, 136. https://doi.org/10.1301/nr.2003.apr.136-138

Submit or recommend next manuscript to SCIRP and we will provide best service for you:

Accepting pre-submission inquiries through Email, Facebook, LinkedIn, Twitter, etc. A wide selection of journals (inclusive of 9 subjects, more than 200 journals)

Providing 24-hour high-quality service

User-friendly online submission system

Fair and swift peer-review system

Efficient typesetting and proofreading procedure

Display of the result of downloads and visits, as well as the number of cited articles

Maximum dissemination of your research work

Submit your manuscript at: http://papersubmission.scirp.org/

Or contact jdm@scirp.org 